\title{
Seasonal Variation in Neuroendocrine and Mood Responses to IV L-Tryptophan in Depressed Patients and Healthy Subjects
}

Angela Cappiello, M.D., Ph.D., Robert T. Malison, M.D., Christopher J. McDougle, M.D., Sally J. Vegso, M.S., Dennis S. Charney, M.D., George R. Heninger, M.D., and Lawrence H. Price, M.D.

Seasonality of mood disorders might involve alterations in the rhythmicity of serotonin [5-HT] function. We examined seasonal effects on the neuroendocrine and mood responses to L-tryptophan (L-TRP) in depressed patients and healthy subjects. In this study, 126 drug-free patients with DSM-III-R major depression and 58 healthy subjects received in IV infusion of L-TRP. Serum prolactin (PRL) and plasma tryptophan levels were measured. Mood was assessed with visual analogue scales. Cosinor analysis revealed seasonal variation in peak change $(\Delta) P R L$ and baseline tryptophan levels in the combined depressed and in unipolar, nonmelancholic, and nonpsychotic patients. Peak $\triangle P R L$ and tryptophan levels were inversely correlated in combined depressed and unipolar patients. Seasonality was more evident in female than in male patients. These data support previous evidence that 5-HT function is abnormal in depression and further suggest a seasonal variability of such abnormalities that is absent in healthy subjects. (C) 1996 American College of Neuropsychopharmacology [Neuropsychopharmacology 15:475-483, 1996]
KEY WORDS: Serotonin; Depression; Seasonality; Tryptophan; Prolactin; Mood disorders

Seasonal variation has been described in several psychiatric conditions (Wirz-Justice 1995) including mood disorders, seasonal affective disorders (SAD) (Rosenthal et al. 1984), alcoholism (Poikolainen 1982), aggressive disorders (Michael and Zumpe 1983), and bulimia (Rosenthal et al. 1987). Moreover, seasonality has been reported in the severity of depression and in the occurrence of vio-

From the Clinical Neuroscience Research Unit (RTM, CJM, SJV, GRH, LHP), Abraham Ribicoff Research Facilities, Connecticut Mental Health Center; Psychiatry Service (AC, DSC), West Haven VA Medical Center; Department of Psychiatry (AC, RTM, CJM, SJV, DSC, GRH, LHP), Yale University School of Medicine, New Haven, Connecticut.

Address correspondence to: L.H. Price, M.D., Clinical Neuroscience Research Unit, Department of Psychiatry, Yale University School of Medicine, 34 Park Street, New Haven, CT 06519.

Received June 26, 1995; revised November 15, 1995; accepted February 16,1995 . lent suicide (Maes et al. 1993a,b). Epidemiologic studies show that depression peaks in the spring and fall (Eastwood and Stiasny 1978), whereas mania occurs more often in summer (Carney et al. 1988). A peak incidence of suicide in May and October has been reported in over 20 studies (Goodwin and Jamison 1990). Recent data suggest that the seasonality of some conditions, such as major depression, violent suicide, and SAD, might be related to alterations in the rhythmicity of serotonin (5-hydroxytryptamine [5-HT]) function (Brewerton 1989).

Studies of 5-HT function in humans can be grouped according to whether measures are static (e.g., biochemical levels in body fluids or blood elements) or dynamic (e.g., neuroendocrine responses to pharmacologic provocation) (Price et al. 1990a,b). Several lines of evidence based on static measures support the hypothesis of 5-HT seasonal variation in humans: (1) hypothalamic 5-HT levels in post-mortem brain specimens are decreased in winter after values peak in the fall (Carlsson 
et al. 1980); (2) platelet 5-HT uptake and ${ }^{3}[\mathrm{H}]$-imipramine (IMI) binding show a seasonal pattern (albeit with some differences in seasonal peaks and troughs) (Whitaker et al. 1984; Tang and Morris 1985; DeMet et al. 1989); (3) serum levels of melatonin, a hormone derived from 5-HT, demonstrate summer and winter peaks in healthy males (Arendt et al. 1977); (4) plasma levels of the 5-HT precursor tryptophan show a spring trough in healthy subjects (Maes et al. 1995); and (5) levels of 5-HT and its metabolites in cerebrospinal fluid (CSF) show seasonal fluctuation, varying with the latitude and the population studied (Åsberg et al. 1980). The variability in the specific seasonal peaks and nadirs reported by different investigators reflects the use of different research designs, methods, sample sizes, and measures of 5-HT function. Furthermore, the statistical methods used have varied from those more accurate in detecting biological rhythms (e.g., cosinor analysis, spectral analysis) to those less sensitive (e.g., $t$-tests, analysis of variance).

In depression, evaluation of 5-HT seasonality is complicated by abnormalities in 5-HT function intrinsic to the disorder (Heninger et al. 1984; Meltzer and Lowy 1987; Van de Kar 1989; Charney et al. 1991; Delgado et al. 1992). Among studies utilizing static measures, some have detected a parallel 5-HT rhythm in depressed compared with healthy subjects (Arora et al. 1984; Chicz-De Met et al. 1991; DeMet et al. 1991), but others have observed no differences between the two groups (Whitaker et al. 1984; Egrise et al. 1986; Kanof et al. 1987).

Few studies of seasonal variation in humans have used dynamic measures of 5-HT function. Brewerton (1989) described higher prolactin (PRL) responses to the 5-HT receptor agonist $m$-chloro-phenylpiperazine (mCPP) during winter in 36 bulimic patients and 15 healthy controls. Using the 5-HT releaser d,l-fenfluramine, Coiro et al. (1993) observed blunted PRL and cortisol responses in seven seasonal affective disorder (SAD) patients compared with eight healthy subjects, but no seasonal differences were detected. In contrast, Joseph-Vanderpool et al. (1993) described seasonal variation in the behavioral response (activation/euphoria) to $\mathrm{MCPP}$ in 10 winter SAD patients compared with eight summer SAD patients. To our knowledge, seasonal variation of dynamic 5-HT function has not been assessed in depressed patients not specifically selected for seasonality.

This study examines seasonal effects on the neuroendocrine and mood responses to IV infusion of the 5-HT precursor L-tryptophan (L-TRP) in 126 depressed patients and 58 healthy subjects. We (Heninger et al. 1984; Price et al. 1991) and others (Koyama and Meltzer 1986; Cowen and Charig 1987; Deakin et al. 1990) have previously observed blunted neuroendocrine responses to L-TRP in depressed patients when seasonality was not taken into account.

\section{SUBJECTS AND PROCEDURES}

\section{Subjects}

As previously described (Price et al. 1991), 126 depressed patients and 58 healthy controls gave voluntary written informed consent to participate in this study, conducted at the Clinical Neuroscience Research Unit of the Connecticut Mental Health Center, New Haven, CT. The geographical coordinates for the study site were $41.1^{\circ} \mathrm{N}$ and $72.5^{\circ} \mathrm{W}$. The study span extended from January 26, 1983 until June 26, 1987. All subjects were free of serious medical conditions, based on complete physical and neurologic examinations, electrocardiogram, and screening laboratory tests.

All patients met DSM-III-R criteria for a principal diagnosis of major depression and had a score $\geq 18$ on a 25-item version of the Hamilton Depression Rating Scale (HDRS) (Hamilton 1960). Substance abuse or dependence, schizophrenic or other psychoses, organic mental disorders, and obsessive compulsive disorder (OCD) were exclusionary criteria. Comorbidity with anxiety disorders other than OCD was not an exclusionary criterion. Diagnoses were made by consensus of the authors based on residents' and nurses' assessments, family evaluation, medical records, interview with the Yale Depressory Inventory (Mazure et al. 1986), and direct interview. Healthy controls were obtained by newspaper advertisements and by referral from other healthy volunteers. In addition to the medical screening described above, they were also screened for a personal or family history of mental disorder by a research psychiatrist using a semi-structured interview. Controls were paid to participate.

Demographic and clinical characteristics for the entire sample, including DSM-III-R depressive subtype, age, gender, weight, and HDRS score, are provided in Table 1.

\section{Study Procedures}

Patients were studied during a placebo period preceding a single-blind antidepressant drug trial. At the time of testing, patients had been receiving placebo for at least 2 weeks and had been free of psychotropic drugs (except for low-dose benzodiazepines for severe agitation and insomnia) for at least 3 weeks. Healthy controls were unmedicated and additionally agreed to refrain from alcohol use for at least 2 weeks and other psychoactive drug use for at least 4 weeks before testing.

Subjects fasted overnight and throughout the 3-hour test, which began at 9:00 A.M. in a specially designated challenge room. The test dose consisted of L-TRP $7 \mathrm{~g} \mathrm{IV}$ infused over a 20-minute period. Subjects remained awake in a supine position with head elevated during the procedure. Blood sampling for PRL was performed 
Table 1. Demographic and Clinical Characteristics of Depressed Patients and Healthy Subjects

\begin{tabular}{|c|c|c|c|c|c|c|}
\hline \multirow[b]{2}{*}{ Group } & \multicolumn{2}{|c|}{ Age (years) } & \multicolumn{2}{|c|}{ Sex } & \multicolumn{2}{|c|}{$\begin{array}{c}\text { Hamilton } \\
\text { Depression } \\
\text { Score } \\
(25 \text { items })\end{array}$} \\
\hline & Mean & SD & $\mathbf{M}$ & $\mathbf{F}$ & Mean & SD \\
\hline Healthy subjects $(n=58)$ & 38 & 13 & 17 & 41 & - & - \\
\hline All depressed $(n=126)$ & $43^{a}$ & 14 & 38 & 88 & 33 & 10 \\
\hline Unipolar $(n=109)$ & $44^{b}$ & 14 & 31 & 78 & 34 & 11 \\
\hline Bipolar $(n=17)$ & 40 & 15 & 7 & 10 & 30 & 7 \\
\hline Melancholic $(n=68)$ & $47^{c}$ & 15 & 21 & 47 & 36 & 10 \\
\hline Nonmelancholic $(n=58)$ & 38 & 10 & 17 & 41 & 30 & 10 \\
\hline Psychotic $(n=28)$ & $45^{d}$ & 15 & 6 & 22 & 40 & 10 \\
\hline Nonpsychotic $(n=98)$ & $43^{r^{\prime}}$ & 13 & 32 & 66 & 31 & 10 \\
\hline
\end{tabular}

All comparisons are between depressive subtype group and healthy subjects.

$a_{t}=2.6, d f=182, p<.02$.

${ }^{b} t=2.8, d f=165, p<.007$.

${ }^{c} t=3.8, d f=124, p<.0002$.

$d_{t}=2.2, d f=84, p<.03$.

${ }^{c} t=2.3, d f=154, p<.03$.

through an indwelling intravenous cathether kept patent by a slow saline drip. Sampling began at least 1 hour after catheter insertion, and 15 minutes before ("baseline") and 30, 40, 50, 60, 70, and 90 minutes after the start of the L-TRP infusion. Visual analog scales $(0 \mathrm{~mm}=$ "not at all," $100 \mathrm{~mm}=$ "most ever") on 13 different mood states (talkative, happy, drowsy, nervous, sad, calm, depressed, anxious, energetic, fearful, mellow, high, angry) were scored by the patients at these times (omitting the 70-minute time point). At the same times, sitting pulse and blood pressure were measured with a sphygmomanometer in the usual clinical fashion. Blood samples for basal plasma trptophan were obtained 15 minutes before the infusion.

\section{Biochemical Methods}

The L-TRP infusions were prepared by dissolving $8.4 \mathrm{~g}$ of L-TRP in $600 \mathrm{ml}$ of $0.45 \%$ saline solution, with $50 \%$ $\mathrm{NaOH}$ added to bring the solution to $\mathrm{pH}$ 7.4. Each $600-\mathrm{ml}$ aliquot was sterilized by passage though a $0.22-\mathrm{mm}$ filter (Millipore) and was tested for pyrogenicity and sterility before use. Serum samples were assayed for PRL levels using a radioimmunoassay kit from Serono Diagnostics, Inc., with intraassay and interassay coefficients of variation (CV) of $3 \%$ and $7 \%$, respectively. Total plasma tryptophan concentration was measured in 35 patients and 28 controls by high performance liquid chromatography, with intraassay and interassay CVs of $2.1 \%$ and $6.8 \%$, respectively. Each assay was carried out in duplicate.

\section{Data Analysis}

Dates of sampling were evaluated for uniform distribution over the course of a calendar year. Analysis of seasonal variation was conducted separately for depressed and healthy subjects on baseline and peak change $(\Delta)$ plasma PRL, baseline plasma TRP, and peak $\Delta$ mood responses using the cosinor method. Peak $\Delta$ was calculated by subtracting the baseline score from the highest value after L-TRP administration. Because peak $\Delta$ PRL responses and baseline plasma tryptophan were inversely correlated (Price et al. 1991), peak $\Delta$ PRL levels were evaluated using baseline tryptophan levels as a covariate. These residualized values were then used in the cosinor analysis. Because depressed and healthy subjects differed significantly in age (cf. Table 1) and because previous studies suggest that age may be a factor in seasonality (LaCoste and Wirz-Justice 1989), age was also used as a covariate in all analyses. Seasonal best fits of the variables were determined by multiple linear regression, using $X 1=\operatorname{Cos}(2 \pi \times D A Y / 365), X 2=\operatorname{Sin}(2 \pi \times$ $\mathrm{DAY} / 365)$, and age as independent variables. The estimated seasonal peak (acrophase) and seasonal trough were determined from the regression equation for those seasonal best fits that were statistically significant. The mesor (expected average of individual levels if these values were over 1 year) and the amplitude (maximum ordinate value of the sinusoidal curve) were determined by linear regression, with $\mathrm{X}=\operatorname{Cos}[2 \pi \times(\mathrm{DAY}$ ACROPHASE) $/ 365$ ] as the independent variable (Bingham et al. 1982; De Meyer and Vogelaere 1991; DeMet et al. 1991).

Biochemical and mood variables were also analyzed for seasonal differences within and between diagnostic groups (patients vs. controls) by analysis of covariance (ANCOVA), using age as the covariate. The cosinor method and ANCOVAs were then used to examine seasonal variation by gender and specific depressive subgroups (unipolar/bipolar; melancholic/nonmelancholic; psychotic/nonpsychotic) for each variable when the initial analysis of that variable was significant. Pearson correlations were used to evaulate the relationships between the PRL response to IV L-TRP and baseline tryptophan levels during each season.

All statistical tests were two-tailed, with significance at $p<.05$. Data were analyzed using SPSS version 4.0 (SPSS 1990).

\section{RESULTS}

\section{Subject Characteristics}

The distribution of the sampling dates was evaluated (Table 2). A normal probability plot of the sampling dates showed a pattern consistent with a uniform distribution $(p<.002$ for lack of normality, Kolmogorov- 
Table 2. Seasonal Distribution of Sampling Dates for Healthy Subjects and Depressive Subgroups

\begin{tabular}{lcccc}
\hline & Winter & Spring & Summer & Autumn \\
\hline Healthy subjects & 14 & 14 & 10 & 20 \\
All depressed & 32 & 27 & 31 & 36 \\
Unipolar & 30 & 26 & 22 & 31 \\
Bipolar & 2 & 1 & 9 & 5 \\
Nonmelancholic & 17 & 11 & 14 & 16 \\
Melancholic & 15 & 16 & 17 & 20 \\
Nonpsychotic & 22 & 21 & 27 & 28 \\
Psychotic & 10 & 6 & 4 & 8 \\
\hline
\end{tabular}

Smirnov test), with median, 25th percentile, and 75th percentile sampling points on days 181,81 , and 276 , respectively.

Table 1 shows that the combined depressed group was significantly older than the healthy group. Age difference was also significant for the unipolar, melancholic, nonpsychotic, and psychotic groups, whereas there was no significant age difference between bipolar and healthy subjects. Neither combined nor subtyped depressed groups differed significantly from healthy controls in sex ratio.

\section{Prolactin}

Baseline PRL did not fit to a sinusoidal function in either healthy controls or depressed patients, nor were significant findings evident by ANCOVA.

Residualized peak $\triangle$ PRL response after L-TRP infusion in the combined depressed group showed a significant seasonal variation, which fitted to a 12 -month sinusoidal function $(\mathrm{F}=10.7, d f=1,107, p<.001)$, with a seasonal peak on February 15, seasonal trough on July 24 , mesor $=10.1 \mathrm{ng} / \mathrm{ml}$, and amplitude $= \pm 0.9 \mathrm{ng} / \mathrm{ml}$ (Figure 1). Peak $\Delta$ PRL in the depressed patients also fitted to a 4-month sinusoidal model $(\mathrm{F}=4.7, d f=3,105$, $p<.003$; acrophase, April 10; trough, February 4; mesor = $1.1 \mathrm{ng} / \mathrm{ml}$; amplitude $= \pm 10.2 \mathrm{ng} / \mathrm{ml}$ ). Peak $\Delta$ PRL in the healthy controls did not fit to a 12-month sinusoidal curve, nor to 1-, 3-, 4-, or 6-month sinusoidal models. Significant 12-month seasonal variation in peak $\Delta$ PRL was present in unipolar $(\mathrm{F}=3.9, d f=3,91, p<.01$; seasonal peak, February 15; seasonal trough, July 24; mesor = $10.1 \mathrm{ng} / \mathrm{ml} ;$ amplitude $= \pm 1.1 \mathrm{ng} / \mathrm{ml}$ ), nonmelancholic $(\mathrm{F}=3, d f=3,43, p<.03$; peak, February 18; trough, June 27; mesor $=9.4 \mathrm{ng} / \mathrm{ml}$; amplitude $= \pm 1.2 \mathrm{ng} / \mathrm{ml}$ ), and nonpsychotic $(\mathrm{F}=2.9, d f=3,82, p<.03$; peak; December 28; trough, June 4 ; mesor $=9.9 \mathrm{ng} / \mathrm{ml}$; amplitude $= \pm 0.7 \mathrm{ng} / \mathrm{ml}$ ) depressed patients (Figure 1). Seasonality was not detected in bipolar, melancholic, or psychotic patients. No gender differences were detected in either healthy subjects or depressed patients. ANCOVAs of peak $\triangle$ PRL responses revealed no significant findings either within or between the main diagnostic groups.

\section{Plasma Tryptophan}

Baseline plasma tryptophan levels fitted to a 12-month sinusoidal function in depressed patients $(\mathrm{F}=3.5, p<$ .01 ), but not in healthy subjects, with a seasonal peak on July 24, trough on January 24, mesor $=7.6 \mu \mathrm{g} / \mathrm{ml}$, and amplitude $= \pm 0.7 \mu \mathrm{g} / \mathrm{ml}$ (Figure 2). Significant seasonal variation in plasma tryptophan was also detected in unipolar $(\mathrm{F}=4.0, p<.009$; peak, July 24; trough, February $18 ;$ mesor $=7.6 \mu \mathrm{g} / \mathrm{ml}$; amplitude $= \pm 0.8 \mathrm{ng} / \mathrm{ml}$ ), nonmelancholic ( $\mathrm{F}=3.3, p<.02$; peak, June 27; trough, February 18; mesor $=8.2 \mu \mathrm{g} / \mathrm{ml}$; amplitude $= \pm 1.0$ $\mu \mathrm{g} / \mathrm{ml}$, and nonpsychotic $(\mathrm{F}=2.9, p<.03$; peak, June 4; trough, December 6; mesor $=7.8 \mu \mathrm{g} / \mathrm{ml}$; amplitude $=$ $\pm 0.6 \mu \mathrm{g} / \mathrm{ml}$ ) patients (Figure 2). Bipolar, melancholic, and psychotic patients did not fit to a sinusoidal function. A trend toward significance for gender-specific seasonal pattern was detected only in the combined depressed females $(\mathrm{F}=2.6, p<.054)$. ANCOVA of plasma tryptophan was significant in the combined de-

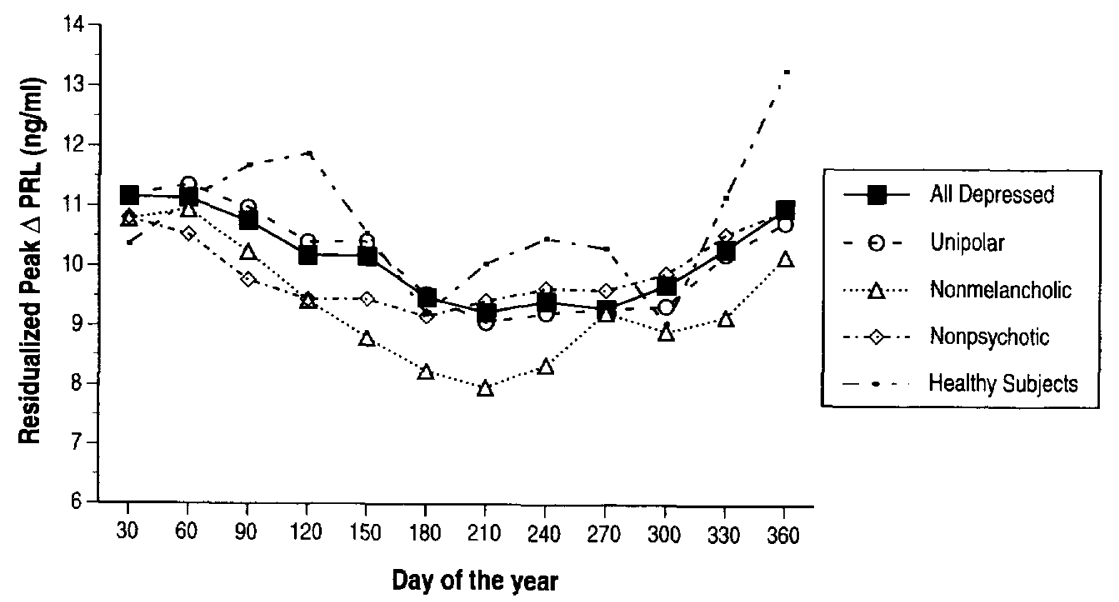

Figure 1. Seasonal variation of residualized peak $\triangle$ PRL response to L-TRP in healthy subjects and all depressed, unipolar, nonmelancholic, and nonpsychotic subgroups (cosinor analysis with baseline plasma tryptophan and age as covariates; to simplify presentation, monthly means are plotted). 




Figure 2. Seasonal variation of baseline plasma tryptophan in all depressed, unipolar, nonmelancholic, and nonpsychotic subgroups (cosinor analysis with age as a covariate; to simplify presentation, monthly means are plotted). pressed group $(\mathrm{F}=2.7, d f=3,105, p<.04)$, but not in healthy controls. Subsequent ANCOVAs showed significant seasonal variation only in the psychotic subgroup $(\mathrm{F}=3.3, d f=3,68, p<.02)$, and there were no significant gender differences. A significant negative correlation was found between peak $\Delta$ PRL and plasma tryptophan levels during winter $(r=-0.47, p<.02)$ and summer $(r=-0.49, p<.008)$ in the combined depressed patients. The same negative correlation was maintained in unipolar depressed patients in winter $(r=-0.53, p<.01)$ and summer $(r=0.45, p<.04)$, but not in nonmelancholic and nonpsychotic patients.

\section{Mood Responses}

Subjective mood responses to L-TRP did not fit to sinusoidal functions in either depressed patients or healthy controls, nor were ANCOVAs of mood responses significant.

\section{DISCUSSION}

Using the cosinor method, this study detected seasonal variation (Table 3 ) (winter peak, summer trough) in the peak $\Delta$ PRL response to IV L-TRP in depressed patients, but not in healthy subjects. Baseline plasma tryptophan levels also displayed seasonal variation (summer peaks, winter troughs) in depressed, but not in healthy, subjects. Furthermore, a significant negative correlation between peak $\Delta$ PRL and baseline plasma tryptophan was found during winter and summer in depressed patients. Previous studies have demonstrated blunting of both the PRL response to IV L-TRP in depressed patients compared with controls (Heninger et al. 1984; Koyama and Meltzer 1986; Cowen and Charig 1987; Deakin et al. 1990; Price et al. 1991). Our data suggest that there are qualitative differences in the seasonality of these responses within these groups. However, such differences do not seem to account for the magnitude of blunted responses in depression (Brewerton 1992; Price et al. 1992), because no season $x$ diagnosis interactions were detected by ANCOVA.

Significant seasonal variation was evident only in specific depressive subgroups. For example, unipolar, nonmelancholic, and nonpsychotic patients showed winter peaks and summer troughs in the peak $\Delta$ PRL response, while simultaneously showing summer peaks and winter troughs in baseline plasma tryptophan.

The present data suggest a possible relationship between seasonal changes in neuroendocrine and biochemical measures of 5-HT function and the seasonal recurrence of mood disorders. One of our major findings was a winter peak and summer trough in the PRL response to L-TRP in depressed patients. Interestingly, Wehr et al. (1993) found that sleep time and blood levels of melatonin and PRL were increased in simulated winter photoperiods in healthy volunteers. It would be reasonable to hypothesize that the winter peak in the PRL response to $\mathrm{L}$-TRP relates to other biological rhythms (e.g., sleep, light-dark cycle, weight, appetite, gonadotropins) that can be altered in depression. However, it is difficult to interpret how the timing of the most blunted PRL responses (summer) or the greatest PRL response (winter) relate to the occurrence of such

Table 3. Seasonal Peaks/Troughs in Measures of 5-HT Function in Depressed Patients and Healthy Subjects (12-month model)

\begin{tabular}{|c|c|c|c|c|}
\hline Group & $\begin{array}{l}\text { Baseline } \\
\text { PRL }\end{array}$ & $\begin{array}{c}\text { Peak } \Delta \text { PRL } \\
\text { (peak/trough) }\end{array}$ & $\begin{array}{l}\text { Mesor } \\
(\mathrm{ng} / \mathrm{ml})\end{array}$ & $\begin{array}{c}\text { Amplitude } \\
(\mathrm{ng} / \mathrm{ml})\end{array}$ \\
\hline Healthy subjects & NS & NS & & \\
\hline All depressed & NS & Feb 15/Jul 24 & 10.1 & 0.9 \\
\hline Unipolar & NS & Feb 15/Jul 24 & 10.1 & 1.1 \\
\hline Bipolar & NS & NS & & \\
\hline Melancholic & NS & NS & & \\
\hline Nonmelancholic & NS & Feb 18/Jun 27 & 9.4 & 1.2 \\
\hline Psychotic & NS & NS & & \\
\hline Nonpsychotic & NS & Dec $28 /$ Jun 4 & 9.9 & 0.7 \\
\hline
\end{tabular}


clinical phenomena as the peak incidences of depression and suicide (spring and fall).

The summer peak and winter trough of plasma tryptophan levels detected in depressed patients must be considered in light of the dependence of central 5-HT synthesis on such levels (Young and Teff 1989). Numerous studies have found decreased plasma tryptophan levels in depressed patients (Joseph et al. 1984; Maes et al. 1987; Cowen et al. 1989; Russ et al. 1990), although others have failed to confirm this (Riley and Shaw 1976; Møller et al. 1979). In the only previous study of seasonal variation, Swade and Coppen (1980) also observed that free tryptophan levels in depressed patients showed a summer peak, although they found that this pattern was the reverse of that seen in healthy controls. Cowen and Charig (1987) reported that baseline tryptophan levels were lower in depressed patients with significant weight loss and with PRL response to IV L-TRP greater than controls. Consistent with this is our finding in depressed patients that lower tryptophan levels correlated with higher PRL responses to L-TRP during summer and winter, the seasons in which PRL responses troughed and peaked while plasma tryptophan levels peaked and troughed. This suggests that seasonal variation in central 5-HT function in depression may be related to seasonal changes in tryptophan availability or metabolism.

Evidence of diagnostic subtype specificity for nonmelancholic patients in the seasonality of PRL responses is notable given that our previous analysis of these data found blunting of the PRL response to be clearest in the same group (Price et al. 1991). Although we did not evaluate our patients for a diagnosis of SAD, it must be considered that the typical symptom profile of this syndrome (increased appetite, weight gain, hypersomnia, fatigue, decreased physical activity, depressed mood, irritability) (Rosenthal et al. 1984; Blehar and Lowy 1990) is most consistent with patients in our nonmelancholic group. This raises the possibility that SAD patients in our sample may have contributed to our finding of seasonal variation in the PRL response. Abnormal 5-HT function in SAD has been hypothesized by others, with reports of increased neuroendocrine responses to mCPP (Jacobsen et al. 1987; GarciaBorreguero et al. 1995) and blunted responses to to fenfluramine (Coiro et al. 1993), but normal responses to the 5-HT precursor 5-hydroxytryptophan (Jacobsen et al. 1989). As noted previously, seasonal variation in 5-HT-mediated responses in SAD has been inconsistent (Coiro et al. 1993).

There has been only one previous report using IV L-TRP as a dynamic probe of 5-HT function seasonality in humans. Brewerton (1989) found significant seasonal differences between a subgroup of nonanorectic bulimic patients and heathly controls in response to L-TRP. In the same report, a winter peak for the PRL response to oral mCPP was observed in both patients and controls. In addition to the obvious diagnostic differences between studies, Brewerton (1989) evaluated seasonality using analysis of variance but not the cosinor method.

Static measures of 5-HT function, such as platelet 5-HT uptake and ${ }^{3}[\mathrm{H}]-\mathrm{IMI}$ binding, have been reported to show seasonal variation, although with some inconsistency in the timing of peaks and troughs. Egrise et al. (1986) described a peak $\mathrm{B}_{\max }$ of ${ }^{3}[\mathrm{H}]-\mathrm{IMI}$ binding and $\mathrm{V}_{\text {max }}$ of 5-HT uptake in September and October, respectively, in seven depressed patients. DeMet et al. (1991), assessing ${ }^{3}[\mathrm{H}]$-IMI binding in 49 depressed patients and 20 controls, reported lower than normal $B_{\max }$ in the depressed group, with an acrophase on January 19. Acrophase values of $V_{\max }$ were observed by Arora et al. (1984) in fall and winter in 82 depressed and 104 normal subjects, with lower $V_{\max }$ in depressed patients throughout the year. Swade and Coppen (1980) described seasonal variation in $V_{\max }$ in 26 depressed patients, with troughs in May-June and peaks in January-February. Malmgren (1989) reported abnormally low platelet 5-HT uptake in 64 depressed patients compared with 120 controls, with $V_{\max }$ peak values in October-November.

Some limitations of the present study deserve comment. First, data came from different subjects throughout the year rather than repeated measures on the same subjects. However, the large sample $(n=184)$ balances this weakness. A year-long longitudinal study of 5-HT function in acutely depressed subjects would not be methodologically or ethically feasible. Furthermore, several studies have shown the same outcome when cross-sectional and longitudinal methods were compared (Wirz-Justice and Richter 1979; Reinberg 1974). However, Maes et al. (1995) were recently able to detect seasonal variation of plasma tryptophan in a year-long study of 26 healthy subjects.

Second, the cosinor method tends to minimize patterns with greater fluctuations that might have occurred on a semiannual, quarterly, or monthly basis. Secondary analyses using cosinor fits to 1-, 3-, 4-, or 6-month models generally failed to identify significant patterns in the present data. The sole exception to this was the fit of peak $\triangle$ PRL response to a 4-month model in the depressed patients, although the neurobiological significance of this isolated finding is unclear. However, the cosinor method allowed us to evaluate variability and magnitude of seasonal rhythms (Wirz-Justice and Richter 1979), which we could not have detected using analysis of variance; it also minimized the influence of individual outliers that could have significantly altered monthly means (DeMet et al. 1990).

Third, our database did not enable us to identify patients with SAD. This would have been particularly useful in further elucidating the seasonal variations observed in our nonmelancholic subgroup.

Our data are consistent with previous evidence that 
central 5-HT function is abnormal in depressed patients and further suggest a seasonal variability of such abnormalities that is absent in healthy subjects. Concentration of these findings in unipolar and nonmelancholic patients raises the possibility that both 5-HT dysfunction and seasonal variation may be of particular relevance to the pathophysiology of depression in these groups. Additional studies will be important to assess the clinical significance of these findings.

\section{ACKNOWLEDGMENTS}

This work was supported in part by grants $\mathrm{MH}-25642, \mathrm{MH}-$ 30929, MH-36229, and MH-00579 from the U.S. Public Health Service, Bethesda, Maryland, by Young Investigator Awards (Drs. Cappiello, McDougle, and Malison) from the National Alliance for Research in Schizophrenia and Affective Disorders, by Stanley Foundation Research Awards (Drs. Price and Heninger), and by the Department of Mental Health, Connecticut. The clinical and research staffs of the Clinical Neuroscience Research Unit provided expert assistance. Elizabeth Kyle prepared the manuscript. The authors thank Edward DeMet, Ph.D., for advice concerning the statistical analysis.

\section{REFERENCES}

Arendt J, Wirz-Justice A, Bradtke J (1977): Annual rhythm of serum melatonin in man. Neurosci Lett 7:327-330

Arora RC, Kregel L, Meltzer HY (1984): Seasonal variation of serotonin uptake in normal controls and depressed patients. Biol Psychiatry 19:795-804

Åsberg M, Bertilsson L, Rydin E, Schalling D, Thorén P, Träskman-Bendz L (1980): Monoamine metabolites in cerebrospinal fluid in relation to depressive illness, suicidal behaviour and personality. In Angrist B, Burrows GD, Lader M, et al. (eds), Recent Advances in Neuropharmacology. Oxford, Pergamon, pp 257-271

Bingham C, Arbogast B, Cornelissen G, Lee J, Halberg F (1982): Inferential statistical methods for estimating and comparing cosinor parameters. Chronobiologia 9:397439

Blehar MD, Lowy AJ (1990): Seasonal mood disorders: Consensus and controversy. Psychopharmacol Bull 26:465494

Brewerton TD (1989): Seasonal variation of serotonin function in humans. Research and clinical implications. Ann Clin Psychiatry 1:153-164

Brewerton TD (1992): Serotonin function in depression: Effects of seasonality? [Letter to the Editor] Am J Psychiatry 149:1277

Carlsson A, Svennerholm L, Winblad B (1980): Seasonal and circadian monoamine variations in human brains examined post mortem. Acta Psychiatr Scand 280(suppl): $75-83$

Carney PA, Fitzgerald CT, Monaghan CE (1988): Influence of climate on the prevalence of mania. Br J Psychiatry 152:820-823
Charney DS, Delgado PL, Price LH, Heninger GR (1991): The receptor sensitivity hypothesis of antidepressant action: A review of antidepressant effects on serotonin function. In Brown S-L, Van Praag HM (eds), The Role of Serotonin in Psychiatric Disorders. New York, Brunner/ Mazel, pp 27-56

Chicz-DeMet A, Reist C, DeMet EM (1991): Relationship between seasonal patterns of platelet serotonin uptake and $3 \mathrm{H}$-imipramine binding in depressed patients and normal controls. Prog Neuro-Psychopharmacol Biol Psychiatry 15:25-39

Coiro V, Volpi R, Marchesi C, De Ferri A, Davoli C, Caffarra P, Rossi G, Caffarri G, Davolio M, Chiodera P (1993): Abnormal serotonergic control of prolactin and cortisol secretion in patients with seasonal affective disorder. Psychoneuroendocrinology 18:551-556

Cowen PJ, Charig EM (1987): Neuroendocrine responses to intravenous tryptophan in major depression. Arch Gen Psychiatry 44:958-966

Cowen PJ, Parry-Billings M, Newsholme EA (1989): Decreased plasma tryptophan levels in major depression. J Affective Disord 16:27-31

De Meyer F, Vogelaere P (1991): Spectral resolution of cardio-circulatory variations in men measured by autorhythmometry over 2 years. Int J Biometeorol 34:105121

Deakin JFW, Pennell I, Upadhyaya AJ, Lofthouse R (1990): A neuroendocrine study of serotonin function in depression: Evidence for biological mechanisms of endogenous and psychosocial causation. Psychopharmacology 101:85-92

Delgado PL, Price LH, Heninger GR, Charney DS (1992): Neurochemistry. In Paykel ES (ed), Handbook of Affective Disorders, 2nd ed. Edinburgh, UK, Churchill Livingstone, pp 219-253

DeMet EM, Bell KM, Reist C, Gerner RH, Chicz-DeMet A (1990): Seasonal changes in cyanoimipramine specific platelet $3 \mathrm{H}$-imipramine binding in depression. Psychiatry Res 34:315-329

DeMet EM, Chicz-DeMet A, Fleischmann J (1989): Seasonal rhythm of platelet $3 \mathrm{H}$-imipramine binding in normal controls. Biol Psychiatry 26:489-495

DeMet EM, Reist C, Bell KM, Gerner JH, Chicz-DeMet A, Warren S, Wu J (1991): Decreased seasonal mesor of platelet $3 \mathrm{H}$-imipramine binding in depression. Biol Psychiatry 29:427-440

Eastwood MR, Stiasny S (1978): Psychiatric disorder, hospital admission, and season. Arch Gen Psychiatry 35:769771

Egrise D, Rubinstein M, Schoutens A, Cantraine F, Mendlewicz J (1986): Seasonal variation of platelet serotonin uptake and $3 \mathrm{H}$-imipramine binding in normal and depressed subjects. Biol Psychiatry 21:283-292

Garcia-Borreguero D, Jacobsen FM, Murphy DL, JosephVanderpool JR, Chiara A, Rosenthal NE (1995): Hormonal responses to the administration of $\mathrm{m}$-chlorophenylpiperazine in patients with seasonal affective disorder and control. Biol Psychiatry 37:740-749

Goodwin FK, Jamison KR (1990): Manic-Depressive Illness. New York, Oxford University Press 
Hamilton M (1960): A rating scale for depression. J Neurol Neurosurg Psychiatry 23:56-62

Heninger G, Charney DS, Sternberg DE (1984): Serotonergic function in depression: Prolactin response to intravenous tryptophan in depressed patients and healthy subjects. Arch Gen Psychiatry 41:398-402

Jacobsen FM, Muller EA, Rogers SLB, Rosenthal NE (1989): The role of serotonin in seasonal affective disorders and the antidepressant response to phototherapy. In Rosenthal NE, Blehar MC (eds), Seasonal Affective Disorders and Phototherapy. New York, Guilford Press, pp 333-341

Jacobsen FM, Sack DA, Wehr TA, Rogers S, Rosenthal NE (1987): Neuroendocrine response to 5-hydroxytryptophan in seasonal affective disorder. Arch Gen Psychiatry 44:1086-1091

Joseph MS, Brewerton TD, Reus VI, Stebbins GT (1984): Plasma L-tryptophan/neutral amino acid ratio and dexamethasone suppression in depression. Psychiatry Res 11:185-192

Kanof PD, Coccaro EF, Johns CA, Siever LJ, Davis KL (1987): Platelet $3 \mathrm{H}$-imipramine binding in psychiatric disorders. Biol Psychiatry 22:270-286

Koyama T, Meltzer HY (1986): A biochemical and neuroendocrine study of the serotonergic system in depression. In Iippius II, Klerman GL, Matussek N (eds), New Results in Depression Research. Berlin/Heidelberg, Springer-Verlag, pp 169-188

LaCoste V, Wirz-Justice A (1989): Seasonal variation in normal subjects: An update of variables current in depression research. In Rosenthal NE, Blehar MC (eds), Seasonal Affective Disorders and Phototherapy. New York, Guilford Press, pp 167-229

Maes M, De Ruyter M, Hobin P, Suy E (1987): Relationship between the dexamethasone suppression test and the L-tryptophan/competing amino acid ratio in depression. Psychiatry Res 21:323-335

Maes M, Meltzer HY, Suy E, De Meyer F (1993a): Seasonality in severity of depression: Relationships to suicide and homicide occurrence. Acta Psychiatr Scand 88:156-161

Maes M, Cosyns P, Meltzer HY, De Meyer F, Peeters D (1993b): Seasonality in violent suicide but not in nonviolent suicide or homicide. Am J Psychiatry 150:1380-1385

Maes M, Scharpé S, Verkerk R, D'Hondt P, Peeters D, Cosyns P, Thompson P, De Meyer F, Wauters A, Neels $H$ (1995): Seasonal variation in plasma L-Tryptophan availability in healthy volunteers. Arch Gen Psychiatry 52:937-946

Malmgren R, Åberg-Wistedt A, Martensson B (1989): Aberrant seasonal variations of platelet serotonin uptake in endogenous depression. Biol Psychiatry 25:393-402

Mazure C, Nelson JC, Price LH (1986): Reliability and validity of the symptoms of major depressive illness. Arch Gen Psychiatry 43:451-456

Meltzer HY, Lowy MT (1987): The serotonin hypothesis of depression. In Meltzer HY (ed), Psychopharmacology: The Third Generation of Progress. New York, Raven Press, pp 513-526

Michael RP, Zumpe D (1983): Sexual violence in the United States and the role of season. Am J Psychiatry 140:883886
Møller SE, Kirk L, Honoré P (1979): Free and total plasma tryptophan in endogenous depression. J Affective Disord 1:69-76

Poikolainen K (1982): Seasonality of alcohol-related hospital admissions has implications for prevention. Drug Alcohol Depend 10:65-69

Price LH, Charney DS, Delgado PL, Goodman WK, Krystal JH, Woods SW, Heninger GR (1990a): Clinical data on the role of serotonin in the mechanism(s) of action of antidepressant drugs. J Clin Psychiatry 51(suppl 4):44-50.

Price LH, Charney DS, Delgado PL, Goodman WK, Krystal JH, Woods SW, Heninger GR (1990b): Clinical studies of 5-HT function using i.v. L-tryptophan. Prog Neuro-Psychopharmacol Biol Psychiatry 14:459-472

Price LH, Charney DS, Delgado PL, Heninger GR (1991): Serotonin function and depression: Neuroendocrine and mood responses to intravenous L-tryptophan in DSM-III-R depressive subtypes and healthy controls. Am J Psychiatry 148:1518-1525

Price LH, Delgado PL, Charney DS, Heninger GR (1992): In reply to "Serotonin function in depression: Effects of seasonality?" (Letter to the Editor). Am J Psychiatry 149:1277

Reinberg A (1974): Aspects of circannual rhythms in man. In Pengelley ET (ed), Circannual Clocks: Annual Biological Rhythms. New York, Academic Press, pp 423-509

Riley CJ, Shaw DM (1976): Total and nonbound tryptophan in unipolar illness. Lancet ii:1249

Rosenthal NE, Genhart M, Sack DA, Skwerer RG, Wehr TA (1987): Seasonal affective disorder and its relationship to the understanding and treatment of bulimia. In Hudson JI, Pope HG (eds), The Psychobiology of Bulimia. Washington, DC, American Psychiatric Press, pp 203-228

Rosenthal NE, Sack DA, Gillin JC, Lewy AJ, Goodwin FK, Davenport Y, Mueller PS, Newsome DA, Wehr TA (1984): Seasonal affective disorder. A description of the syndrome and prelminary findings with light therapy. Arch Gen Psychiatry 41:72-80

Russ MJ, Ackerman SH, Banay-Schwartz M, Shindledecker RD, Smith GP (1990): Plasma tryptophan to large neutral amino acid ratios in depressed and normal subjects. J Affective Disord 19:9-14

SPSS $^{\circledR}$ Base System User's Guide (1990): Norusis MJ (ed) Chicago, SPSS Inc.

Swade C, Coppen A (1980): Seasonal variations in biochemical factors related to depressive illness. J Affective Disord 2:249-255

Tang SW, Morris JM (1985): Variation in human platelets 3H-imipramine binding. Psychiatry Res 16:141-146

Van de Kar LD (1989): Neuroendocrine aspects of the serotonergic hypothesis of depression. Neurosci Biobehav Rev 13:237-246

Joseph-Vanderpool JR, Jacobsen FM, Murphy DL, Hill JL, Rosenthal NE (1993): Seasonal variation in behavioral responses to $m$-CPP in patients with seasonal affective disorder and controls. Biological Psychiatry 33:496-504

Wehr TA, Moul DE, Barbato G, Giesen HA, Seidal JA, Barker C, Bender C (1993): Conservation of photoperiodresponsive mechanisms in humans. Am J Physiol 265 (Regulatory Integrative Comp. Physiol. 34):R846-R857 
Whitaker PM, Warsh JJ, Stancer HC, Persade E, Vint CK (1984): Seasonal variation in platelet $3 \mathrm{H}$-imipramine binding: Comparable values in control and depressed populations. Psychiatry Res 11:127-131

Wirz-Justice A (1995): Biological rhythms in mood disorders. In Bloom FE, Kupfer DJ (eds), Psychopharmacology: The Fourth Generation of Progress. New York, Raven Press, 999-1017
Wirz-Justice A, Richter R (1979): Seasonality in biochemical determinations: A source of variance and a clue to the temporal incidence of affective illness. Psychiatry Res $1: 53-60$

Young SN, Teff KL (1989): Tryptophan availability, 5HT synthesis and 5HT function. Prog Neuro-Psychopharmacol Biol Psychiatry 13:373-379 